\title{
Luchas políticas y legitimación religiosa en Esparta tras la guerra del Peloponeso (404-371 a. C.)
}

\section{Political struggles and religious legitimacy in Sparta after the Peloponnesian War (404-371 BC)}

\author{
JAVIER JARA HERRERO \\ Universidad de Salamanca \\ javijara@usal.es
}

Resumen: El final de la guerra del Peloponeso confirió a los espartanos la hegemonía política sobre la Hélade y la posibilidad de interferir más allá de las fronteras griegas. Sin embargo, el siglo IV a. C. fue también testigo de la agudización de las tensiones en el seno de la clase dirigente de Esparta y de la unión de diversos estados en contra del dominio lacedemonio. Mediante el análisis de las fuentes antiguas y con el apoyo de las investigaciones de la historiografía moderna, este artículo trata de examinar la influencia ejercida por la religión en Esparta hasta la batalla de Leuctra, tanto en su política exterior como en las diversas luchas políticas internas.

Palabras clave: Esparta, religión, legitimación, luchas políticas, hegemonía.

Abstract: The end of the Peloponnesian War conferred on the Spartans the political hegemony over Hellas and the option of interfering beyond Greek border areas. However, the 4th century BC also was a witness of the tensions' aggravation within the ruling elite of Sparta and the union of various states against the Spartan domain. This paper tries to analyse, through the study of ancient sources and with the support of investigations from modern historiography, the influence exerted by religion in Sparta up to the Battle of Leuctra, both in its foreign policy and in the various internal political struggles.

Keywords: Sparta, Religion, Legitimacy, Political struggles, Hegemony.

Recibido: 9 de marzo de 2020; aceptado: 13 de julio de 2020; publicado: 30 de septiembre de 2020.

Revista Historia Autónoma, 17 (2020), pp. 11-29

e-ISSN: 2254-8726; https://doi.org/10.15366/rha2020.17.001 


\section{Introducción}

La rendición de Atenas en la primavera del 404 a. C. marcó el final de la guerra del Peloponeso y, con ello, el comienzo de la preponderancia espartana a través de la Hélade ${ }^{1}$. Los lacedemonios difundieron, ya desde antes del comienzo de la guerra que centró la obra del historiador Tucídides, una propaganda en la que se presentaban como liberadores de los griegos frente a la tiranía ejercida por los atenienses y su imperio talasocrático materializado en la liga ático-délica. No obstante, el mundo helénico tardó poco en percatarse de que la victoria de las armas espartanas, lejos de constituir tal libertad, solo significó un cambio de dueño en la mayoría de las poleis afectadas, pues Lisandro, el arquitecto del triunfo final de Esparta al dirigir la escuadra peloponesia que venció a la ateniense en la batalla naval de Egospótamos (405 a. C.), estableció progresivamente regímenes de naturaleza oligárquica (fieles no solo a Esparta, sino al propio Lisandro), las llamadas "decarquías"2, en las ciudades que tomó. La implantación de estos sistemas políticos, integrados por diez individuos, fue acompañada de un incesante caudal de riquezas hacia una polis que procuraba mantener el espejismo de armonía e igualdad socioeconómica de sus ciudadanos ${ }^{3}$. Una de las primeras acciones emprendidas por las autoridades espartanas y, en concreto, por el artífice de la victoria de Egospótamos merced a la llegada de capital tras la guerra fue la de inmortalizar su victoria en un formidable monumento levantado en el santuario de Delfos, un complejo escultórico en el que se mostraba a Lisandro acompañado de cada uno de los navarcos de la escuadra peloponesia junto a dos estrellas de oro en honor de los Dioscuros ${ }^{4}$.

Los espartanos tenían motivos para celebrar su triunfo en Delfos. El santuario se había convertido en uno de los centros religiosos más importantes de la Hélade y, tras la segunda guerra médica, el mundo griego pareció olvidar la sospechosa inclinación medizante del oráculo para convertirlo en un escaparate en el que los diferentes estados escribían su historia y exhibían su poder. Esta tendencia se fue agudizando conforme avanzó el siglo v a. C., de manera que, en las últimas décadas de esta centuria, las poleis más poderosas hicieron lo posible por procurarse el respaldo de Apolo a su causa, bien mediante donaciones económicas, bien mediante suntuosas construcciones que dejaran en evidencia a las ofrendadas por aquellas que pudieran disputar la hegemonía, conscientes de que el control del santuario de Delfos implicaba casi inexorablemente el control político sobre Grecia ${ }^{5}$. Por ello, el monumento con

\footnotetext{
${ }^{1}$ Vid. Parke, Herbert W., "The Development of the Second Spartan Empire (405-371 B. C.)", en Journal of Hellenic Studies, 50 (1930), pp. 37-79, quien acuñó, al respecto, la etiqueta de "segundo imperio espartano", ya en desuso. ${ }^{2}$ En lo que respecta a las decarquías y a su naturaleza, es útil Carlier, Pierre, Le IVe siècle grec jusqu'à la mort d'Alexandre, París, Éditions du Seuil, 1995, pp. 15-17.

${ }^{3}$ Cf. Xen., Lac. 7.

${ }^{4}$ Plut., Lys. 18, 1; Paus., 10, 9, 9.

${ }^{5}$ Dicho control en relación con el oráculo ya desató la "segunda guerra sagrada" a mediados del siglo v a. C., en la que Esparta disputó a la Atenas de Pericles su hegemonía en torno al lugar sagrado y, consecuentemente, sobre Grecia central: Gómez Espelosín, F. Javier, "El santuario de Delfos y la guerra”, en Pérez Jiménez, Aurelio
} 
el que Esparta honró a Lisandro triplicaba en tamaño al instalado décadas antes por Atenas tras la batalla de Maratón, manifestando a los peregrinos quiénes eran los artífices del nuevo orden geopolítico ${ }^{6}$. Las razones de los lacedemonios, sin embargo, tenían raíces más profundas. Esparta fue una de las poleis que más abusó del recurso a la religión para legitimar sus medidas políticas, ya fueran estas en materia interna o externa. Su organigrama constitucional, atribuido al mítico legislador Licurgo y compilado siglos después por Jenofonte en su Constitución de los lacedemonios $^{7}$, fue hipotéticamente refrendado por la sacerdotisa délfica y dotado de un carácter sacro que le permitió una cierta inmutabilidad frente a los intentos de reforma ${ }^{8}$. Los lacedemonios fueron además los únicos que contaban con unos personajes responsables de la relación con el santuario, unas figuras encargadas de realizar las consultas y de custodiar las profecías oraculares denominadas "pitios" por Heródoto".

Así, Esparta trató en todo momento de mantener activos sus vínculos con Delfos, al tiempo que la clase sacerdotal del santuario, como forma pragmática de garantizar su supervivencia, supo obtener réditos de esta relación bilateral. Se estableció, por lo tanto, una simbiosis entre ambas entidades que explica que, al comenzar la guerra del Peloponesoen el 431 a. C., las autoridades délficas se encontraran en plena sintonía con los intereses peloponesios. Prueba de ello es el apoyo manifestado por la pitia al ser interpelada acerca de la pertinencia de una declaración de guerra espartana, cuya respuesta, según Tucídides, fue que "si combatían con todas sus fuerzas, la victoria sería suya, y les declaró que Apolo mismo les ayudaría, tanto si era

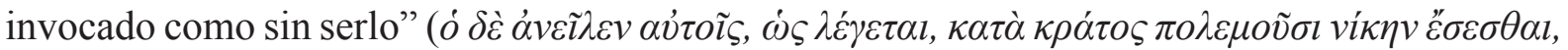

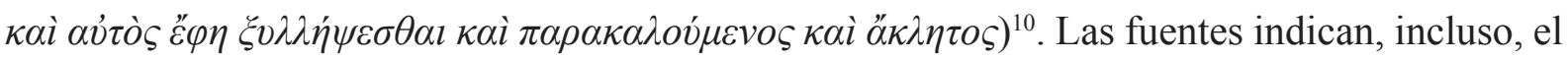
patronazgo económico de Delfos a los esfuerzos bélicos espartanos durante la primera fase de la guerra, lo que se desprende del discurso corintio de la asamblea de la liga del Peloponeso que el mismo Tucídides recogió en su obra ${ }^{11}$. No es de extrañar, teniendo en cuenta estos hechos, que el final de la guerra del Peloponeso representara el apogeo de la conexión entre Esparta y el oráculo délfico. Ambas entidades se beneficiaban mutuamente: los lacedemonios mediante los vaticinios píticos favorables a sus intereses, y el colegio sacerdotal délfico a través de las donaciones que, desde Esparta, llegaban al santuario ${ }^{12}$.

\footnotetext{
y Gonzalo Cruz Andreotti (eds.), La religión como factor de integración y conflicto en el Mediterráneo, Madrid, Ediciones Clásicas, 1996, pp. 26-53. Sobre el oráculo en general: Scott, Michael, Delfos. Historia del centro del mundo antiguo, Barcelona, Editorial Ariel, 2015.

${ }^{6}$ Ibídem, p. 137.

${ }^{7}$ Vid. David, Ephraim, "Xénophon et le mythe de Lycurgue”, en Ktéma, 32 (2007), pp. 297-310.

${ }^{8}$ Tyr., 3 Diehl; Hdt., 1, 65, 3; Pl., Leg. 691D-E; Plut., Lyk. 6, 1-2.

${ }^{9}$ Hdt., 6, 57, 2-4.

${ }^{10}$ Th., $1,118,3$.

${ }^{11}$ Th., 1, 121.

${ }^{12}$ Para profundizar en los obsequios ofrendados a Delfos por Esparta y el resto de estados griegos en la segunda mitad del siglo v a. C., vid. Scott, Michael, Delfos... op. cit., pp. 157-179.
} 
2. La relación lacedemonia con el santuario de Olimpia tras el 404 a. C.

El triunfo espartano sobre Atenas representó asimismo un punto de inflexión en las relaciones de Esparta con instituciones religiosas. Especialmente tensos eran los contactos con el otro santuario panhelénico del momento, el de Zeus en Olimpia (situación de la que Delfos salió beneficiada al acaparar toda la atención lacedemonia) $)^{13}$. En el 421 a. C., poco antes de que la "paz de Nicias" paralizara las hostilidades, Élide, el estado democrático en el que se encontraba el santuario olímpico, sufrió la defección de Lépreo, una de sus comunidades periecas, que decidió interrumpir el pago de su tributo poniendo como pretexto las operaciones de la guerra. Cuando los eleos intentaron imponerse mediante la fuerza, la localidad perieca se acogió al arbitraje espartano y consiguió el apoyo de Esparta, que estableció una guarnición y animó a otros colectivos periecos a seguir el ejemplo. En consecuencia, Élide se negó a firmar la "paz de Nicias" y las relaciones entre este estado y el lacedemonio se congelaron ${ }^{14}$, hasta el punto de que los espartanos llegaron a ser expulsados de los Juegos Olímpicos del 420 a. C. ${ }^{15}$. Reanudadas las hostilidades entre Esparta y Atenas, los eleos se mantuvieron neutrales hasta el final de la conflagración y recuperaron Lépreo, una vez que los espartanos necesitaron utilizar los servicios de la guarnición que estableció anteriormente. En la última fase de la guerra, los eleos volvieron a humillar a las autoridades espartanas:

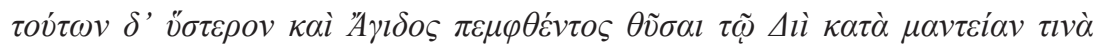

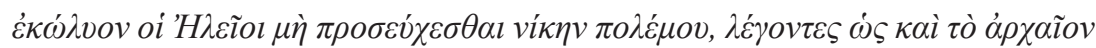

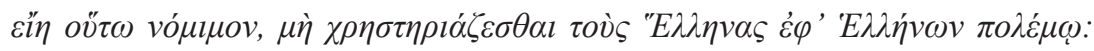
$\omega ̋ \sigma \tau \varepsilon \ddot{\alpha} \theta v \tau o \varsigma \dot{\alpha} \pi \tilde{\eta} \lambda \theta \varepsilon v$.

Cuando Agis fue enviado para sacrificar a Zeus de acuerdo con un oráculo, los eleos le impidieron rogar por la victoria alegando que incluso desde antiguo estaba prescrito así: que los griegos no consultaran un oráculo en una guerra contra griegos. En consecuencia, se marchó sin sacrificar. ${ }^{16}$

\footnotetext{
${ }^{13}$ Parke, Herbert W. y Donald E. Wormell, The Delphic Oracle. Volume I: The History, Chicago, Ares Publishers, 1956 , p. 203. Acerca de las relaciones entre Esparta y el santuario de Olimpia, consúltese Thommen, Lukas, "Spartas Verhältnis zu Elis und Olympia", en Birgalias, Nikos et al., War-peace and panhellenic games: in memory of Pierre Carlier, Atenas, Institut du livre A. Kardamitsa, 2013, pp. 329-344, https://doi.org/10.3917/dha.hs92.0013 ${ }^{14}$ Vid. Fornis, César, "Esparta y la Cuádruple Alianza", en Memorias de Historia Antigua, 13/14 (1992-93), pp. 77103 y Fornis, César, "Corinto, Beocia y la alianza argiva tras la Paz de Nicias", Habis, 26 (1995), pp. 47-66. Sobre las relaciones entre Élide y Esparta en la guerra del Peloponeso, sirvan Alonso Troncoso, Víctor, Neutralidad y neutralismo en la guerra del Peloponeso (431-404 a. C.), Madrid, Ediciones de la Universidad Autónoma de Madrid, 1987, pp. 88-91 y Bauslaugh, Robert A., The Concept of Neutrality in Classical Greece, Berkeley-Los Ángeles, University of California Press, 1991, pp. 168-192.

${ }^{15}$ Th., 5, 50.

${ }^{16}$ Xen., Hell. 3, 2, 22. Traducido por Orlando Guntiñas Tuñón, Madrid, Editorial Gredos, 1994.
} 
Tras el conflicto contra Atenas, Esparta declaró la guerra a la democrática Élide. En los últimos años del siglo v a. C. ${ }^{17}$, los espartanos exigieron la independencia de las comunidades periecas. Ante la negativa elea, Esparta acometió la invasión del territorio del norte del Peloponeso, en una contienda que, para César Fornis, casi podría ser considerada una guerra sagrada por el dominio del santuario olímpico, si bien oficialmente no tuvo tal carácter y trascendieron motivos estratégicos como el dominio sobre los puertos de Cilene y Feax, dado el escaso desarrollo militar de los muelles mesenios ${ }^{18}$. La paz llegó dos años después y, aunque Élide pudo conservar su régimen democrático y no se implantó una guarnición lacedemonia en su territorio, fue obligada a firmar una alianza con Esparta que, con seguridad, otorgaría a esta última un trato más favorable en lo referente al santuario de Olimpia, pese a que su presidencia siguió en manos eleas porque los pisatas, que también reivindicaban la prostasia,

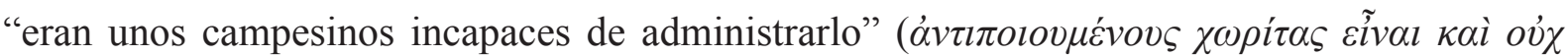

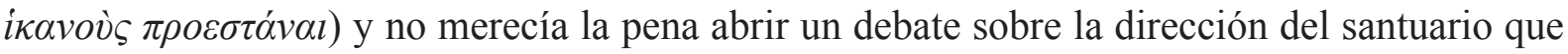
en nada beneficiaría a Esparta ${ }^{19}$. Por lo demás, tras este enfrentamiento se produjo la expulsión de Cefalonia y Naupacto de las poblaciones mesenias, que continuaron su particular diáspora hacia Sicilia o las costas del norte de África ${ }^{20}$, pasando sus antiguos territorios a integrar las fronteras de la confederación aquea, para desgracia tanto de corintios como de tebanos: los primeros por la merma de la salud de su economía, al reducir su influencia sobre el golfo de Corinto $^{21}$; los segundos, debido a su cada vez mayor aislamiento en la zona central de Grecia, rodeados de aliados de los espartanos ${ }^{22}$.

La nueva posición, claramente más ventajosa, de la que disfrutaría Esparta en el santuario de Olimpia no fue el único fruto de su aplastante victoria. El tributo impuesto al estado democrático como miembro de la symmachia liderada por los espartanos pasaría a engrosar aún más su tesoro. Si hemos de creer a Diodoro de Sicilia, en los primeros años del siglo IV a. C. el sistema impositivo sobre los aliados (entendiendo como tales no los miembros de la liga del Peloponeso, sino aquellos que precisaron de la intervención de los hoplitas lacedemonios) reportaba a Esparta la nada desdeñable cantidad de "más de mil talentos cada año" (Évı

\footnotetext{
${ }^{17}$ Diod. Sic., 14, 17, 5 lo fija en el año 402 a. C. Si bien Xen., Hell. 3, 2, 23 retrasa la fecha al 400/399 a. C., Plut., Ages. 40, 3 respalda la cronología que ofrece Diodoro.

${ }^{18}$ Fornis, César, Esparta. La historia, el cosmos y la leyenda de los antiguos espartanos, Sevilla, Ediciones Universidad de Sevilla, 2016, p. 200.

${ }^{19}$ Los términos del tratado de paz pueden encontrarse en Xen., Hell. 3, 2, 30-31. Sobre la prostasia en manos de Élide: Sordi, Marta, "Le implicazioni olimpiche della guerra d'Elide", en Lanzillotta, Eugenio (coord.), Problemi di storia e cultura spartana, Roma, Giorgio Bretschneider Editore, 1984, pp. 145-159. Vid. también Fornis, César, Esparta. La historia,... op. cit., p. 201.

${ }^{20}$ Cf. Domínguez Monedero, Adolfo J., "Locrios y mesenios: de su cohabitación en Naupacto a la fundación de Mesene. Una aproximación al estudio de la diáspora y el 'retorno' de los mesenios", en Polis, 18 (2006), pp. 39-73. ${ }^{21}$ Pascual González, José, "Corinto y las causas de la guerra de Corinto", en Polis, 7 (1995), pp. 188-217; Fornis, César, Estabilidad y conflicto civil en la guerra del Peloponeso: las sociedades corintia y argiva, Oxford, British Archaeological Reports, 1999, pp. 11-12.

${ }^{22}$ Para profundizar en la política beocia durante este periodo: Pascual González, José, Tebas y la confederación beocia en el periodo de la guerra de Corinto (395-386 a. C.), tesis doctoral, Universidad Autónoma de Madrid, 1995 , pp. 469-505.
} 
$\pi \lambda \varepsilon i \omega \omega \tilde{\omega} v \chi l \lambda i \omega v \tau \alpha \lambda \dot{\alpha} v \tau \omega v)^{23}$. Esta recaudación, obviamente, chocaba frontalmente con el carácter liberador que los espartanos se arrogaron durante la guerra del Peloponeso y contribuyó notablemente al descontento de las poleis "liberadas"24.

\section{Legitimaciones religiosas en las luchas políticas de Esparta tras la guerra del Peloponeso}

\section{1. "Una realeza coja": la sucesión de Agis II}

La victoria sobre la liga ático-délica en el 404 a. C. transformó Esparta no solo económicamente, como vemos, sino también socialmente. Una de las señas de identidad de la Esparta de principios del siglo IV a. C. es la radicalización de las diferentes facciones políticas de la clase dirigente espartiata y su conversión en grupos cada vez más antagónicos como resultado de las discrepancias en la gestión de la victoria ${ }^{25}$. Precisamente, uno de estos bandos ${ }^{26}$, a favor del imperialismo lacedemonio fuera de sus fronteras tradicionales peloponesias, fue el encabezado por Lisandro y sus seguidores, detentadores, a la sazón, de los puestos de administración de las decarquías establecidas por el primero ${ }^{27}$. Las tensiones se pusieron de manifiesto tras la muerte del diarca euripóntida Agis II, el que fuera humillado por los eleos en el transcurso de la guerra del Peloponeso (vid. supra). Su hijo Leotíquidas era el primero en la línea de sucesión, pero Lisandro, como representante del nuevo imperio espartano, modeló un

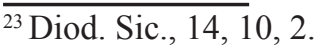

${ }^{24}$ Pascual González, José, Tebas y la confederación ... op. cit., pp. 458-463.

${ }^{25}$ Estudios relacionados con las crecientes disensiones sociales en la Esparta posterior a la guerra del Peloponeso son los de David, Ephraim, "The Influx of Money in Sparta at the End of the Fifth Century B. C.", en Scripta Classica Israelica, 5 (1979), pp. 30-45; Cartledge, Paul, Agesilaos and the Crisis of Sparta, Baltimore, Duckworth, 1987, pp. 99-115; Hodkinson, Stephen, Property and Wealth in Classical Sparta, Swansea, The Classical Press of Wales, 2000, pp. 427-446; Birgalias, Nikos, "La cohésion sociale à Sparte au IV siècle", en Dialogues d'histoire ancienne, 11 (2014), pp. 13-21. El sector escéptico de la historiografía lo encabeza Flower, Michael, "Revolutionary Agitation and Social Change in Classical Sparta", en Flower, Michael y Mark Toher (eds.), Georgica: Greek studies in honour of George Cawkwell, London, University of London, Institute of Classical Studies, 1991, pp. 78-97, cuya investigación concluye que las fricciones sociales fueron leves hasta el siglo III a. C.

${ }^{26}$ Hamilton, Charles D., "Spartan Politics and Policy, 405-401 B. C.", en American Journal of Philology, 91, 3 (1970), pp. 294-314, https://doi.org/10.2307/292953, describe tres proyectos distintos en la Esparta posterior a la guerra del Peloponeso: uno inmovilista en lo referente a las relaciones espartanas con los aliados, liderado por Pausanias; un segundo esquema a favor de aprovechar la hegemonía para ejercer un férreo control sobre los aliados, encabezado por Agis, y, por último, el esgrimido por Lisandro y Agesilao, consistente en aprovechar los restos del imperio ateniense para construir un régimen talasocrático espartano.

${ }^{27}$ Hodkinson, Stephen, "Warfare, Wealth, and the Crisis of the Spartiate Society", en Rich, John y Graham Shipley (eds.), War and Society in the Greek World, London, Routledge, 1995, pp. 151-161, indaga en la alta extracción social de los ocupantes de los puestos de gobierno de las decarquías y apunta que estos cargos se convirtieron en objeto de las ambiciones de la ciudadanía más privilegiada, que vio en estos servicios en el extranjero una forma de enriquecimiento rápido al margen de las estrictas leyes espartanas.
} 
verdadero grupo de presión política y social que vertió sobre el aspirante rumores que apuntaban a su ilegitimidad. En concreto, se alegaba que el hipotético legítimo heredero era fruto de la unión de la reina espartiata Timea con el general ateniense Alcibíades. Según el testimonio de Plutarco, "la sedujo de tal modo, mientras Agis estaba fuera en una expedición, que incluso no negó estar embarazada de Alcibíades y al niño varón que parió, de puertas afuera, lo llamaba

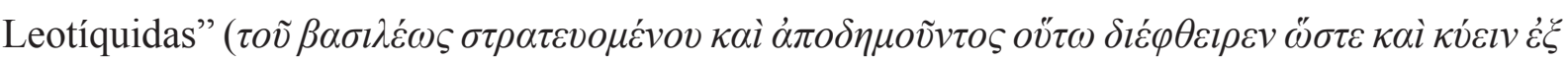

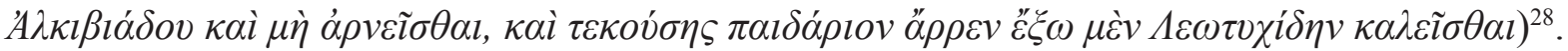

Es probable que el supuesto hijo bastardo del difunto diarca participara de las conservadoras ideas que sostenían la vuelta a las antiguas costumbres espartanas en materia de política exterior, si bien no encontramos fuentes que informen del alineamiento de Leotíquidas. Sí sabemos, por otra parte, que Agesilao, el hermano de Agis, estaba comprometido con la opinión que propugnaba la actitud agresiva de Esparta en el extranjero y que representaría un magnífico contrapunto al rey agíada Pausanias ${ }^{29}$, ferviente defensor de la reducción de la esfera de influencia lacedemonia al Peloponeso. Sea como fuere, Lisandro utilizó su influencia (quizá mermada tras el desmantelamiento de las decarquías) para que, finalmente, el designado fuera Agesilao, con quien, al margen de compartir similares objetivos políticos dentro de un proyecto imperialista, mantuvo una relación amorosa en su juventud con la plausible intención de obtener ulteriores privilegios políticos ${ }^{30}$.

Agesilao era el candidato perfecto para Lisandro: al no ser descendiente directo de Agis, había realizado la agoge y se había convertido en un hombre con un carácter honorable, pero también violento y amante de la guerra. Las dudas sobre los objetivos de Lisandro al adoptar el rol de erastes del futuro diarca se disipan al tomar en consideración que Agesilao, además, hacía gala de un físico poco agraciado y una notable cojera ${ }^{31}$, defecto este último que fue aprovechado por la facción contraria. Un tal Diopites, partidario de la entronización de Leotíquidas y reputado por su capacidad de interpretación de profecías ${ }^{32}$, sacó a la palestra un presunto oráculo délfico referente a los problemas que conllevaría una realeza coja en Esparta:

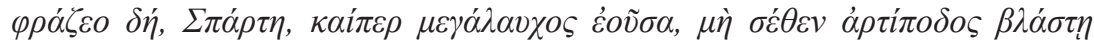

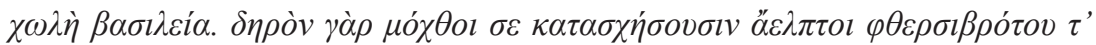

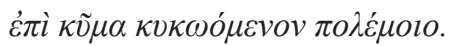

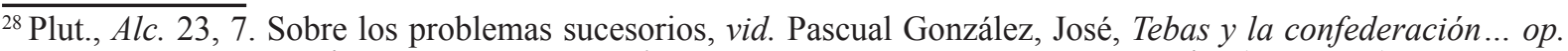
cit., pp. 506-511 y Fornis, César, Esparta. La historia,... op. cit., pp. 207-209. Pausanias (3, 8, 8-10) asegura que el rey Agis solo reconoció a Leotíquidas como heredero legítimo en su lecho de muerte.

${ }^{29}$ Fornis, César, Esparta. La historia, ... op. cit., p. 207.

${ }^{30}$ Murcia Ortuño, Javier, Esparta, Madrid, Alianza Editorial, 2007, p. 289. A propósito de la pederastia institucionalizada en Esparta, sirvan Cartledge, Paul, "The Politics of Spartan Pederasty", en Proceedings of the Cambridge Philological Society, 27 (1981), pp. 17-36; Link, Stefan, "Education and Pederasty in Spartan and Cretan Society", en Hodkinson, Stephen (ed.), Sparta: Comparative Approaches, Swansea, The Classical Press of Wales, pp. 89-102; Singor, Henk W., "Admission to the Syssitia in Fifth-Century Sparta”, en Hodkinson, Stephen y Anton Powell, Sparta. New Perspectives, Swansea, The Classical Press of Wales, 2009, pp. 67-91.

${ }_{31}$ Plut., Ages. 2, 3-4. El biógrafo de Queronea describe al Euripóntida como un hombre "pequeño y de apariencia

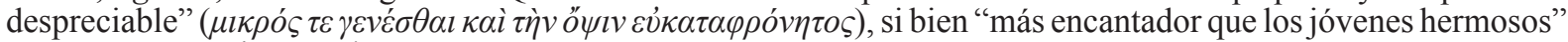

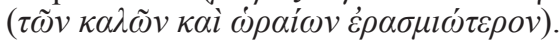

${ }^{32}$ Fornis, César, Esparta. La historia, ... op. cit., p. 207.
} 
Vigila, Esparta, aunque seas orgullosa, no sea que a ti, de pies fuertes, te nazca una realeza coja. Pues durante mucho tiempo penas inesperadas te dominarán, en las olas agitadas de una guerra que hace perecer a los mortales. ${ }^{33}$

El oráculo apolíneo, poco ambiguo para lo que el santuario de Delfos acostumbraba a ofrecer, deja abierta la posibilidad de que se tratara de una invención o un soborno al colegio sacerdotal de Delfos por parte del bando conservador, conocedor de la observancia de los designios délficos en Esparta, y que podría haber servido para que los devotos espartanos desestimaran la idoneidad de Agesilao para ocupar el trono lacedemonio. Sin embargo, la religión no jugó el determinante papel que los seguidores de Leotíquidas deseaban: Lisandro arregló fácilmente la situación aduciendo que la mencionada profecía hacía referencia no a una dolencia física, como la cojera de Agesilao, sino a la posibilidad de que en Esparta reinase un personaje de dudosa ascendencia, en clara referencia a la ilegitimidad que se podría acreditar contra Leotíquidas.

\subsection{El episodio de Áulide}

La controversia en torno a la sucesión del rey Agis II puso en evidencia las luchas intestinas de la clase dominante espartiata. En el año 396 a.C., poco después de su entronización y persuadido por Lisandro, Agesilao II respondió a los rumores que advertían de la construcción de una armada persa que hiciera frente a la lacedemonia con el envío de un ejército a Asia Menor encabezado por el mismo rey ${ }^{34}$, en una campaña no exenta de polémica religiosa. Un buen ejemplo del talante personalista del nuevo diarca lo constituye el episodio de Áulide, que evidenció también las crecientes tensiones con la confederación beocia. De acuerdo con el relato de Plutarco, estando el ejército espartano en el promontorio eubeo de Geresto, Agesilao descendió a Áulide, en la costa de Beocia donde, según Homero, se reunió la gran flota de los griegos en su guerra contra Troya ${ }^{35}$. Allí pasó el diarca la noche y, según el relato de Plutarco (obviamente adornado de elementos místicos), una voz le habría hablado en sueños:

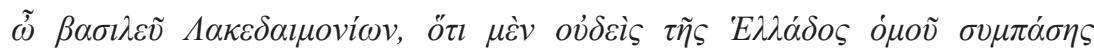

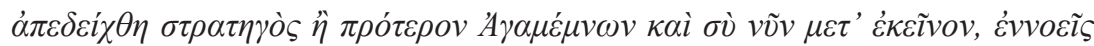

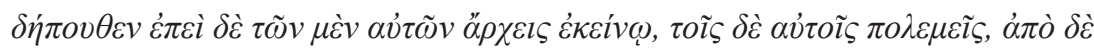

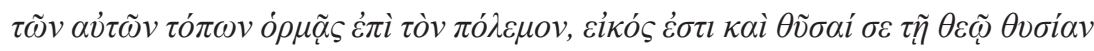

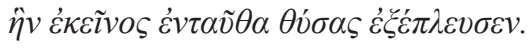

\footnotetext{
${ }_{33}^{3}$ Paus., 3, 8, 9. Traducción de María Cruz Herrero Ingelmo, Madrid, Editorial Gredos, 1994.

${ }^{34}$ La bibliografía sobre la campaña asiática de Agesilao II es ingente: Carlier, Pierre, Le IV siècle grec jusqu'à la mort d'Alexandre... op. cit., pp. 26-28; Lévy, Edmond, Sparte. Histoire politique et sociale jusqu'à la conquête romaine, Paris, Points, 2003, pp. 254-257; Fornis, César, Esparta. La historia, ... op. cit., pp. 214-219. Ruzé, François, "The Empire of the Spartans (404-371)", en Powell, Anton, A Companion to Sparta, Hoboken, Blackwell, 2018, pp. 326-331 son solo algunos ejemplos.

${ }^{35}$ Hom., Il. 2, 303; Cf. Murcia Ortuño, Javier, Esparta ... op. cit., p. 294.
} 
Javier Jara Herrero, "Luchas políticas y legitimación religiosa en...”

Rey de los lacedemonios, que nadie ha sido reconocido general de toda la Grecia unida, salvo antes Agamenón y ahora tú después de él, lo sabes de sobra; puesto que mandas sobre los mismos que él, combates a los mismos enemigos, y partes hacia la guerra desde los mismos lugares, es lógico que también tú hagas en honor de la diosa el mismo sacrificio que hizo él antes de zarpar. $^{36}$

El diarca tenía la intención de establecer un paralelismo entre su expedición asiática y la legendaria lucha de los aqueos de Agamenón que dotase de cobertura ideológica su imperialista política exterior ${ }^{37}$. No obstante, mientras el Euripóntida imitaba el sacrificio del rey micénico a Artemisa (sustituyendo, eso sí, el objeto de ofrenda, que en el caso de Agamenón fue su propia hija Ifigenia, por una cierva), los beotarcos enviaron rápidamente un escuadrón de caballería que interrumpió la ceremonia alegando que el rey espartano no había observado la mántica oficial beocia. Desde este momento, Agesilao guardó un profundo rencor hacia los tebanos ${ }^{38}$.

No fue el único problema al que tuvo que hacer frente el diarca en los primeros años del siglo IV a. C. La campaña asiática también fue el escenario de las desavenencias entre Agesilao y Lisandro, otrora amantes. Plutarco continúa su biografía del primero describiendo su llegada a Éfeso, ya en Asia Menor, donde "la gran consideración y el poder de los que gozaba

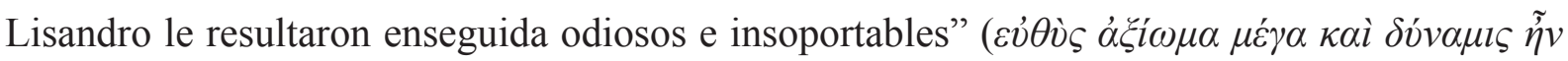

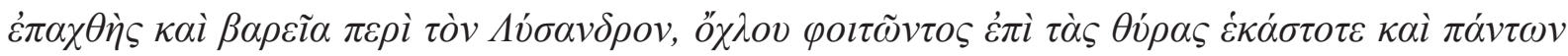

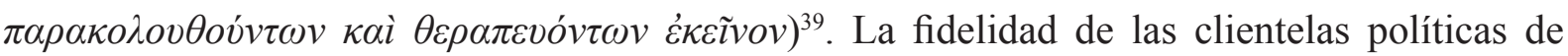
Lisandro superó la egolatría de Agesilao, que, viendo cómo disfrutaba de los agasajos propios de un rey, quiso humillar al primero nombrándole su despensero ${ }^{40}$. Lisandro, consciente del cariz que había tomado la situación, solicitó al rey el mando de una misión militar en el lejano Helesponto, a lo que Agesilao accedió ${ }^{41}$. En palabras de Fornis, "Agesilao mandaba el claro mensaje de que a partir de entonces, él y no otro sería con quien tratarían, y de quien dependerían, las clases acomodadas de los aliados lacedemonios en estas vitales y prósperas áreas geopolíticas del segundo imperio espartano"42.

\footnotetext{
${ }^{36}$ Plut., Ages. 6, 4. Traducción de Jorge Bergua Cavero, Salvador Bueno Morillo y Juan Manuel Guzmán Hermida, Madrid, Editorial Gredos, 2007.

${ }^{37}$ Cf. Bommelaer, Jean-François, "Le songe d'Agesilas: un mythe ou le rêve d'un mythe?", en Ktèma, 7 (1983), pp. 19-26; Ragone, Giuseppe, "L'imitatio Agamemnonis di Agesilao fra Aulide ed Efeso", en Miscellanea Greca e Romana, 20 (1996), pp. 21-49.

${ }^{38}$ Plut., Ages. 6, 9-10. Vid. también Hamilton, Charles D., "Thebes and Sparta in the Fourth Century: Agesilaus' Theban Obsession", en Ktèma, 19 (1994), pp. 239-258; Pascual González, José, Tebas y la confederación beocia ... op. cit., pp. 581-583; Fornis, César, Esparta. La historia, ... op. cit., pp. 214-215.

${ }^{39}$ Plut., Ages. 7, 1.

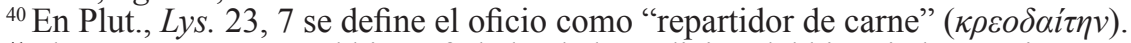

${ }^{41}$ Plut., Ages. 7-8, 43. El biógrafo bebe de la tradición del historiador ateniense Jenofonte (Hell. 3, 4, 7-10), quien, en cambio, no alude al humillante ordenamiento de Lisandro como despensero real.

${ }^{42}$ Fornis, César, Esparta. La historia, ... op. cit., p. 215.
} 


\title{
4. El recurso a la religión en los planes políticos de Lisandro
}

Fue tras esta vergonzosa afrenta cuando Lisandro decidió llevar a cabo su particular desquite. Su intento de controlar a uno de los reyes espartanos con la designación de Agesilao II había fracasado y el vencedor de Egospótamos pensó en un método más radical: modificar el ordenamiento constitucional licurgueo para terminar de un plumazo con la diarquía o, en su lugar, convertirla en una institución de carácter electivo. Los revolucionarios planes de Lisandro no debieron de ser consecuencia directa del trato vejatorio dispensado por Agesilao en Asia Menor, pues Plutarco asegura que fue ese el momento aprovechado para "ponerse manos a la obra y dedicarse sin demora al plan que había pergeñado y maquinado tiempo atrás"

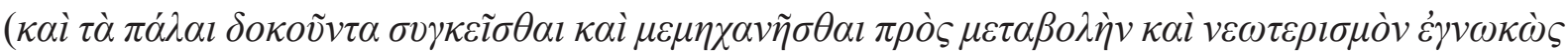

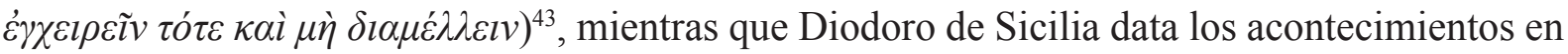
el año 403 a. C. El recurso a la religión por parte de Lisandro es bien descrito por el siciliota:

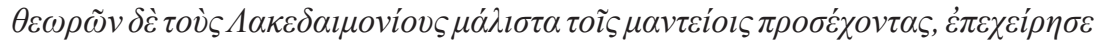

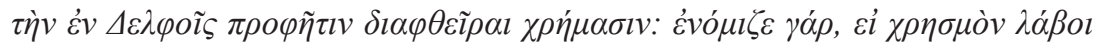

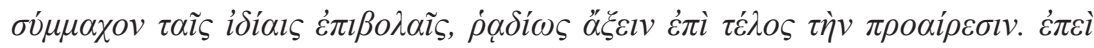

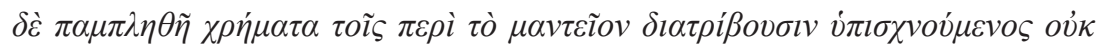

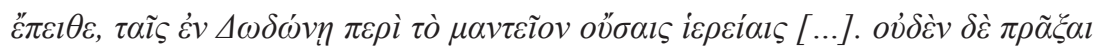

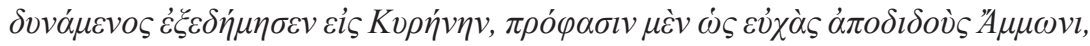

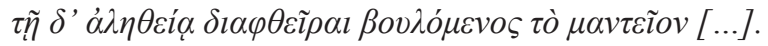

\begin{abstract}
Viendo que los lacedemonios prestaban una extraordinaria atención a las respuestas de los oráculos, trató de corromper con dinero a la sacerdotisa de Delfos; pensaba que si obtenía una respuesta favorable a sus planes, podría fácilmente llevar a término su proyecto. Pero, al no lograr convencer a quienes se ocupaban del oráculo, pese a no dejar de prometerles enormes sumas de dinero, hizo proposiciones del mismo género a las sacerdotisas de Dodona [...]. No pudiendo tampoco conseguir nada, partió a Cirene, con el pretexto de cumplir los votos hechos a Amón, pero en realidad con la intención de corromper el oráculo [...]. ${ }^{44}$
\end{abstract}

La desarticulación de las decarquías habría despojado a Lisandro de la relevancia política adquirida tras la batalla de Egospótamos, de modo que el artífice de la victoria sobre Atenas hubo de buscar alternativas que le brindasen apoyo para llevar a cabo sus planes y, en este sentido, un eventual respaldo religioso resultaría adecuado. Para la consecución de sus pretensiones, Lisandro habría tenido en cuenta los precedentes de otros reyes espartanos como Demarato, que

\footnotetext{
${ }^{43}$ Plut., Lys. 24, 2.

${ }^{44}$ Diod. Sic., 14, 13, 3-5. Traducción de Juan José Torres Esbarranch, Marid, Editorial Gredos, 2008.
} 
fueron depuestos mediante la intervención religiosa de los santuarios de Delfos y Olimpia ${ }^{45}$. En cualquier caso, tal como continúa Diodoro, la negativa de estos centros sagrados hizo fracasar sus planes. De hecho, fue el colegio sacerdotal de Amón el que envió la correspondiente embajada a Esparta para acusar a Lisandro de haber intentado corromper a su oráculo ${ }^{46}$. Con todo, el espartiata consiguió articular una férrea defensa que le valió la absolución en el juicio al que le sometieron los éforos y que no agradó a los dignatarios africanos, quienes, antes de partir de vuelta, espetaron "seremos mejores jueces nosotros cuando vosotros, espartanos, vengáis a vivir con nosotros en Libia” ( $\dot{\alpha} \lambda \lambda$ ’ $\dot{\eta} \mu \varepsilon \tilde{\iota} \varsigma \gamma \varepsilon \beta \varepsilon \dot{\varepsilon} \lambda \tau \imath o v, \tilde{\omega} \Sigma \pi \alpha \rho \tau \imath \tilde{\alpha} \tau \alpha l, \kappa \rho \imath v o \tilde{v} \mu \varepsilon v, o ̈ \tau \alpha \nu$

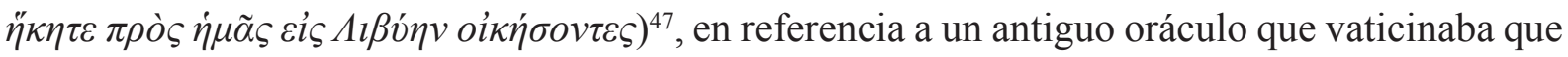
los lacedemonios emigrarían algún día a sus tierras y que se asemeja sospechosamente al que recibieron los habitantes de Tera antes de fundar la colonia de Cirene, compilado por Heródoto de Halicarnaso ${ }^{48}$. Plutarco se hace eco asimismo de otro ardid de Lisandro para terminar con la realeza en Esparta y que con anterioridad habría recogido Éforo: en el Helesponto, donde el espartiata fue destinado tras su encontronazo con Agesilao, existía una mujer que decía estar encinta de la semilla de Apolo, lo que fue vinculado por Lisandro con un hipotético vaticinio de Delfos, que afirmaba que existían antiguas profecías que los sacerdotes del santuario tenían taxativamente prohibido examinar hasta que no llegara un hijo del dios. El hijo de la mujer, al que llamó Sileno, habría acudido al lugar para, en calidad de semidios, leer los oráculos ante la multitud, estipulando uno de ellos que "lo mejor y lo preferible para los espartanos era que los

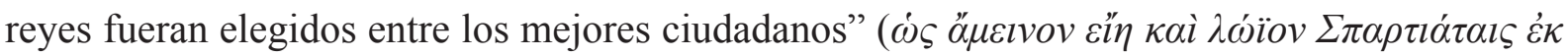

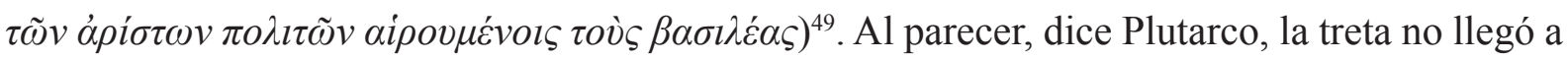
buen puerto porque uno de sus colaboradores finalmente se echó atrás.

Solo después de su muerte, en el 395 a. C., se encontraron en su casa diversos documentos que revelarían su conspiración, en concreto, un elaborado discurso que habría preparado para persuadir a la sociedad espartana de que los gobernantes deberían ser elegidos de entre todos los ciudadanos ${ }^{50}$. Dicho discurso habría sido redactado por un tal Cleón de Halicarnaso, del que solo sabemos que lo habría cobrado a un alto precio, tal como hacían los sofistas $\operatorname{cotizados}^{51}$. Según las fuentes antiguas, el discurso de Cleón era tan peligroso que los éforos recomendaron al diarca Agesilao que no lo sacara a la luz y destruyera las pruebas ${ }^{52}$. La destrucción de esta documentación antes de darse a conocer, como es evidente, plantea el interrogante de la veracidad de esta trama. La enemistad que se fraguó en Asia Menor entre Agesilao y Lisandro pudo dar

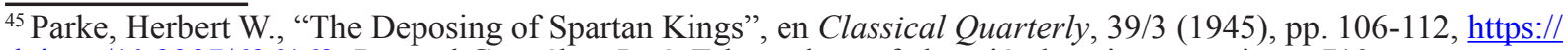
doi.org/10.2307/626162; Pascual González, José, Tebas y la confederación beocia... op. cit., p. 710.

${ }^{46}$ Diod. Sic., 14, $13,7$.

${ }^{47}$ Plut., Lys. 25, 3.

${ }^{48}$ Hdt., 4, 150. Cf. Malkin, Irad, Myth and territory in the Spartan Mediterranean, Cambridge, Cambridge University Press, 1994, pp. 195-196.

${ }^{49}$ Plut., Lys. 26, 3.

${ }^{50}$ Diod. Sic., 14, 13, 8

${ }^{51}$ Cf. Plut., Lys. 25, 1; Nep., Lys. 3.

${ }^{52}$ Fornis, César, Esparta. La historia, ... op. cit., p. 216.
} 
lugar a la creación de una "leyenda negra", recogida por los autores antiguos, especialmente notable en la obra de Jenofonte, y a la que pertenecería también la anécdota de Sileno y los oráculos délficos que debía leer, en torno a la figura de este último que, si bien influyente, no dejaba de estar subordinado al primero. Lisandro fue también el primer griego al que algunas ciudades rindieron culto y levantaron altares, una heroización que chocaba frontalmente con los principios espartanos de igualdad entre sus ciudadanos y que podría haber motivado el recelo de las autoridades lacedemonias ${ }^{53}$. Así, resulta natural el escepticismo de parte de la historiografía moderna al respecto de las ambiciones de Lisandro y de su proyecto de transformar el ordenamiento político espartano ${ }^{54}$, pero, aun así, un amplio sector considera plausible que tratara de reformar la Gran Retra tras la humillación sufrida en Éfeso ${ }^{55}$.

\section{La guerra de Corinto. Fundamentos religiosos espartanos en el conflicto}

La muerte de Lisandro se enmarca en una campaña de castigo que Esparta quiso emprender contra Tebas por su posicionamiento en el conflicto locrio-focidio que precedió la invasión lacedemonia. Comenzada ya la guerra Beocia (395-386 a. C.) ${ }^{56}$, los tebanos, cuyas simpatías por los lacedemonios habían ya desaparecido por completo, persuadieron a sus aliados locrios para que cesaran su tributo a los focidios. Las represalias no se hicieron esperar y, mientras los locrios pidieron el auxilio beocio, las autoridades focidias hicieron lo propio con los espartanos. Deseosa de quebrar el espíritu tebano, Esparta movilizó dos ejércitos y envió antes al mismo Lisandro para que comandara las tropas aliadas focidias con órdenes de esperar al contingente lacedemonio bajo el mando de Pausanias en Haliarto. Pero Lisandro, quien mantenía una vieja rivalidad con el rey, quiso acaparar la gloria de la victoria y atacó las murallas, a cuya sombra pereció al tiempo que sus hoplitas se batían en retirada ${ }^{57}$.

A pesar de su enemistad, Pausanias quiso recobrar el cadáver del que fuera héroe de las armas espartanas (junto con el resto de los cuerpos sin vida de los combatientes lacedemonios) bajo acuerdo, pues su localización hacía prácticamente imposible atacar la posición sin sufrir

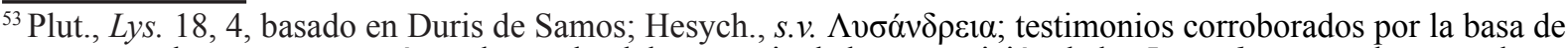
una estatua de un tetracampeón en la prueba del pancracio de la competición de las Lysandreia, nombre con el que se pasó a conocer la fiesta en honor a la diosa Hera, las Heraia. Cf. también Bommelaer, Jean-François, Lysandre de Sparte. Histoire et traditions, París-Atenas, Bibliothèque des Écoles Françaises d'Athènes et de Rome 240, 1981, p. 16.

${ }^{54}$ Flower, Michael A., "Revolutionary Agitation and Social... op. cit., pp. 81-83; Keen, Antony G., "Lies about Lysander", en Papers of the Leeds International Latin Seminar, 9 (1996), pp. 289-290.

${ }^{55}$ Este sector lo encabeza Hamilton, Charles D., "Spartan Politics and Policy, 405-401 B. C.", en American Journal of Philology, 91 (1970), p. 311.

${ }^{56}$ Un completo estudio sobre el conflicto: Fornis, César, Grecia exhausta: Ensayo sobre la Guerra de Corinto, Göttingen, Vandenhoeck \& Ruprecht, 2008.

${ }^{57}$ Vid. Lévy, Edmond, Sparte... op. cit., p. 180-181; Murcia Ortuño, Javier, Esparta ... op. cit., pp. $297-298$.
} 
cuantiosas bajas. Los tebanos, conscientes, solo aceptaron entregar el cuerpo de Lisandro si las tropas de Esparta se retiraban inmediatamente de Beocia. Contraviniendo los deseos de la gerousia, Pausanias recuperó el cadáver, pero fue acusado de cobardía en Esparta y llamado a juicio ${ }^{58}$. El Agíada prefirió no presentarse al proceso, y los éforos le condenaron a muerte por rebeldía, tras lo que hubo de retirarse al templo de Atenea Alea de Tegea como suplicante, donde terminó sus días tras una enfermedad no antes del año 381 a. C. ${ }^{59}$ El cuerpo de Lisandro, por su parte, fue sepultado en el camino que iba de Coronea a Delfos sin que se conozcan más detalles.

Después de la derrota espartana en Haliarto, algunas de las poleis más poderosas de la Hélade contemplaron oportuno el momento para acabar con la hegemonía que el final de la guerra del Peloponeso había otorgado a Esparta. Atenas, Corinto, Tebas y Argos concretaron de este modo un conjunto de symmachiai bilaterales ${ }^{60}$ aprovechando el momento de debilidad institucional que había provocado el exilio del rey Pausanias y la muerte de Lisandro ${ }^{61}$. Los éforos, alarmados, se vieron obligados a solicitar la vuelta a Grecia del rey Agesilao, quien estaba consiguiendo unas decisivas victorias en el interior del reino persa que le permitieron extender la influencia espartana en Asia Menor y, más importante, el reclutamiento de contingentes de griegos minorasiáticos que acompañaron al diarca en su vuelta a Lacedemonia en el 394 a. C. ${ }^{62}$. En una fecha cercana al 14 de agosto de ese año ${ }^{63}$, los espartanos se enfrentaron en igualdad numérica a la coalición antilacedemonia en Coronea. A pesar de la victoria de Esparta, Agesilao debió retirarse para curar sus heridas en Delfos, donde ofreció a Apolo el diezmo del botín

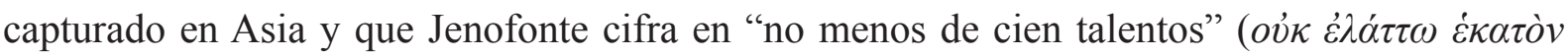
$\tau \alpha \lambda \alpha \dot{\alpha} \tau \tau \omega v)^{64}$ con motivo de los juegos pitios. Las victorias espartanas en Grecia contrastaban con las malas noticias procedentes de Asia, donde Agesilao había dejado una guarnición de cuatro mil guerreros y una flota al mando del navarco Pisandro, hermano de su mujer, con nula experiencia militar. La armada persa, dirigida por Farnabazo, derrotó a la de Pisandro en las cercanías de Cnido en el verano del 394 a. C. y costeó Asia Menor para liberar la mayoría de las ciudades con guarniciones espartanas. En ese momento, Esparta había renunciado a

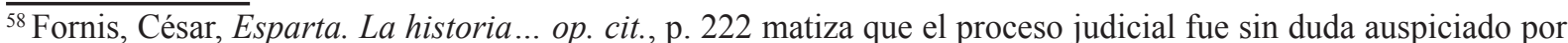
los seguidores del fallecido Lisandro y por Agesilao, contrarios a las políticas conservadoras de Pausanias. Fue el segundo al que se enfrentó el diarca. Paus., 3, 5, 2 informa de la llamada a consultas por parte de las autoridades espartanas tras su infructuosa invasión del Ática en el 403 a. C.

${ }^{59}$ Xen., Hell. 3, 25.

${ }^{60}$ Es difícil catalogar la naturaleza de este sinedrio antilacedemonio. Para profundizar en la cuestión de este y otros pactos de alianza griegos, vid. Alonso Troncoso, Víctor, "Para un corpus de los tratados de alianza de la Grecia clásica", en Dike, 4 (2001), pp. 219-232.

${ }^{61}$ Las fuentes antiguas que informan de la alianza son Xen., Hell. 4, 2, 1; Diod. Sic., 14, 82, 1. Vid. asimismo Fornis, César, "La configuración política y jurídica del synédrion de Corinto (395-394 a. C.)", en Revue Internationale des Droits dans l'Antiquité, 54 (2007), pp. 65-81.

${ }^{62}$ Pascual González, José, Tebas y la confederación ... op. cit., p. 711.

${ }^{63}$ Xen., Hell. 4, 3, 10 informa de un eclipse de sol que la astronomía ha fechado en ese preciso día. Plut., Ages. 17, 4-5 se limita a asegurar que el ejército espartano se encontraba acampado en la localidad el día del fenómeno. ${ }^{64}$ Xen., Hell. 4, 3, 21. Cf. Plut., Ages. 19.
} 
la preponderancia naval en el Egeo y a la forja de un imperio más allá de las fronteras del Peloponeso para defender Grecia continental ${ }^{65}$.

Con la aventura asiática en un segundo plano (pues Agesilao mantuvo en Oriente un ejército de cuatro mil hoplitas al mando del espartiata Euxeno ${ }^{66}$ ), Esparta se centró finalmente en el conflicto que amenazaba la península peloponesia. En el año 387 a. C., los espartanos hicieron los preparativos para atacar Argos, sempiterna rival de Esparta desde el siglo VI a. C. ${ }^{67}$ e integrante del conjunto de poleis que se habían levantado en armas contra la hegemonía lacedemonia. Los diarcas quisieron aprovechar la celebración de las Carneas, fiestas religiosas dorias en honor a Apolo, para llevar a cabo la ofensiva ${ }^{68}$. La táctica de Argos radicaba en aprovechar la inexactitud de su calendario para poder alegar la tregua (o negarla, según las necesidades del momento ${ }^{69}$ ). Los argivos no imaginaron que los ciudadanos de Esparta, en tanto que dorios y devotos, fueran a violar los preceptos que establecían la prohibición de actividades militares durante este festival ${ }^{70}$, pero las autoridades lacedemonias urdieron una inteligente estratagema: Agesípolis, otro diarca en el trono lacedemonio, viajó a Olimpia, al santuario de Zeus, para preguntar al dios "si le era lícito no aceptar las treguas de los argivos, ya que alegaban como pretexto los meses sagrados, no cuando era su época, sino cuando los

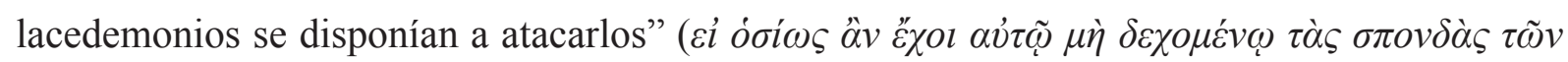

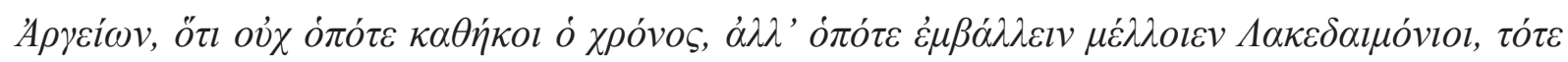

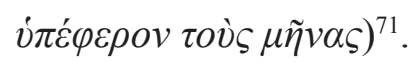

Cabe recordar que el santuario olímpico se encontraba en Élide, estado aliado, si bien forzoso, del lacedemonio tras la guerra que ambos mantuvieron en los últimos años del siglo $\mathrm{V}$ a. C. (vid. supra), por lo que los sacerdotes del lugar sagrado se veían prácticamente obligados a emitir vaticinios favorables a los intereses espartanos. Como era de esperar, el oráculo de Zeus otorgó la aprobación del ataque. Agesípolis viajó entonces a Delfos, menos controlado por Esparta, para preguntar simplemente a Apolo "si pensaba lo mismo que su padre" ( $\kappa \alpha \theta \dot{\alpha} \pi \varepsilon \rho$ $\tau \tilde{\omega} \pi \alpha \tau \rho i)^{72}$. Resultaba complicado que Apolo, siendo hijo de Zeus, no estuviera de acuerdo con su padre, el dueño del Olimpo, y, por extensión, con el oráculo que Agesípolis recibió en Olimpia $^{73}$. Gracias a esta manipulación, pudo llevarse a cabo el ataque contra Argos. Siguiendo la crónica de Jenofonte, después de la victoria espartana se produjo un terremoto que algunos de

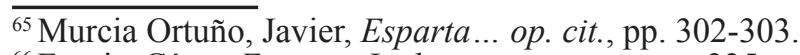

${ }^{66}$ Fornis, César, Esparta. La historia ... op. cit., p. 225.

${ }^{67}$ Vid. Fornis, César y Adolfo J. Domínguez Monedero, "El conflicto entre Argos y Esparta por la Tireátide y el culto a Apolo Piteo", en Gerión, 32 (2014), pp. 79-103.

${ }^{68}$ Acerca del festival de las Carneas, consúltese Richer, Nicolas, "Les 'Karneia' de Sparte”, en Cataldi, Silvio et al., Salvare le poleis, costruire la concordia, progettare la pace, Alejandría (It.)., Edizioni dell'Orso, 2012, pp. 39-69.

${ }^{69}$ Th., 5, 54, 2 describe cómo Argos utilizó su impredecible calendario para atacar y saquear Epidauro en el 419 a. C., en el transcurso de la "paz de Nicias".

${ }^{70}$ Lupi, Marcello, L'ordine delle generazioni. Classi di età e costumi matrimoniali nell'antica Sparta, Bari, Edipuglia, 2000, pp. 61-64; Cartledge, Paul, Los espartanos: una historia épica, Madrid, Ariel, 2009, pp. 107-108. ${ }^{71}$ Xen., Hell. 4, 7, 2.

${ }^{72}$ Ibídem.

${ }^{73}$ Parke, Herbert W. y Donald E. Wormell, The Delphic Oracle... op. cit., pp. 209-210; Scott, Michael, Delfos... op. cit., pp. 184-185.
} 
los soldados lacedemonios atribuyeron a la ira de Poseidón, encolerizado por el atrevimiento de su comandante. Mientras los hoplitas entonaban el peán para calmar a la deidad, Agesípolis se apresuró a replicar que "si hubiera provocado el terremoto cuando se disponía a invadir, habría reconocido que se lo impedía, mas una vez que había invadido, consideraba que lo animaba"

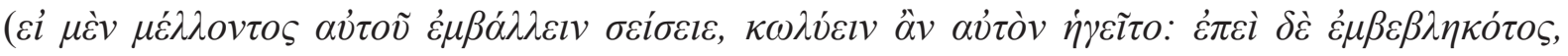

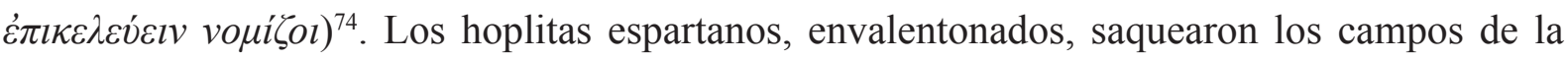
Argólide al día siguiente, pero no consiguieron establecer una base permanente ${ }^{75}$.

Después del episodio concerniente al ataque espartano a Argos del 387 a. C., las fuentes parecen enmudecer en lo que a los contactos entre Esparta y las instituciones religiosas más importantes durante la guerra de Corinto se refiere. Durante el primer cuarto del siglo Iv a. C., Esparta pudo mantener su supremacía y fue conocida por constituir el estado con los vínculos más fuertes con Delfos ${ }^{76}$. La paz de Antálcidas, con la que los espartanos dieron victoriosamente carpetazo a la guerra de Corinto $^{77}$, supuso también el final de la célebre sintonía entre ambas entidades. Si en el siglo anterior las victorias espartanas fueron acompañadas del levantamiento de sofisticados y costosos monumentos en el santuario délfico, tras esta contienda Agesilao II rehusó erigir un memorial en el espacio sagrado, al estilo de su predecesor Agis II tras la victoria sobre Élide ${ }^{78}$, "por considerarlo más propio de hombres ricos que de hombres buenos"

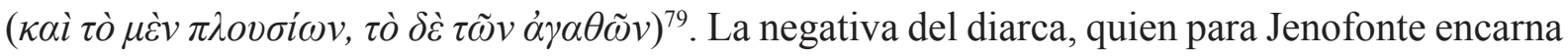
la austeridad propia de un auténtico espartiata y el ideal panhelenista, es quizá una evidencia de que, avanzada la primera mitad del siglo iv a. C., las relaciones con el oráculo de Delfos se habían convertido en una cuestión secundaria para los espartanos, probablemente porque el mantenimiento de su hegemonía hacía menos necesaria la intervención política de la sacerdotisa de Apolo para legitimar sus pretensiones.

\section{El "principio del fin" de la supremacía espartana y la creación del mito délfico}

La "paz de Antálcidas", como imposición del estado hegemónico espartano sobre las poleis vencidas ${ }^{80}$, tuvo como consecuencia la expulsión de la guarnición espartana de la Cadmea

\footnotetext{
$\overline{{ }^{74} \text { Xen., Hell. } 4,7,4 .}$

${ }^{75}$ Paus., 3, 5, 8 .

${ }^{76}$ Parke, Herbert W. y Donald E. Wormell, The Delphic Oracle... op. cit., p. 216.

${ }^{77}$ Cf. Fornis, César, "La paz enviada por el Rey (387/6 a. C.)", en Dike, 10 (2007), pp. 155-183.

${ }^{78}$ Jacquemin, Anne, "Sparte et Delphes du IV siècle av. J.-C. au II ${ }^{\mathrm{e}}$ siècle av. J.-C. Un déclin inscrit dans l'espace sacré", en Dialogues d'histoire ancienne, 11 (2014), p. 136.

${ }^{79}$ Xen., Ages. 11, 7.

${ }^{80}$ Un estudio de los matices de "paz de Antálcidas", sus cláusulas y sus consecuencias es el de Fornis, César, "La paz enviada por el rey... op. cit.
} 
y la derrota de la facción laconizante en Tebas, lo que acabó redundando en la refundación de la Liga Beocia, una asociación de ciudades de la región homónima que quedó bajo el liderazgo de esta polis $^{81}$. El conflicto entre espartanos y beocios alcanzó uno de sus momentos más célebres en el año 371 a. C., en el que se libró la batalla de Leuctra, donde las armas lacedemonias fueron vencidas por el ejército del beotarco Epaminondas y se asestó un duro golpe a la supremacía espartana $^{82}$. Las fuentes nos muestran la indiferencia que los lacedemonios parecían mostrar hacia los dioses, pues parecía que la divinidad daba claras muestras de lo que estaba por acontecer en Esparta. El acontecimiento de Leuctra, aciago momento en la historia espartana, fue anunciado por el santuario de Delfos, como si el propio Apolo hubiera decidido el final de la suerte espartana. Así, Diodoro de Sicilia escribió al respecto:

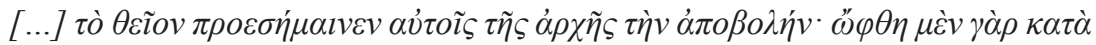

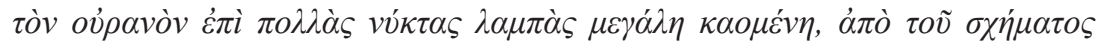

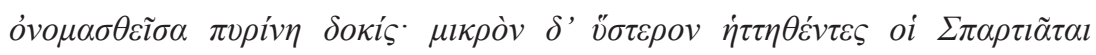

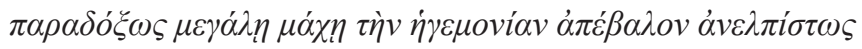

[...] Un presagio enviado por la divinidad les anunció la pérdida de la supremacía; se vio arder en el cielo durante muchas noches una gran antorcha, que, a causa de su forma, fue llamada "la viga de fuego"; y, poco tiempo después los espartiatas fueron derrotados contra toda expectativa en una gran batalla y perdieron inesperadamente su hegemonía. ${ }^{83}$

Plutarco, quien, como hemos visto, se nutre de fuentes susceptibles a la "leyenda negra" forjada en torno a la figura de Lisandro, enlaza el enojo de Apolo con el otrora navarco, haciéndole, quizá, responsable de la decadencia espartana:

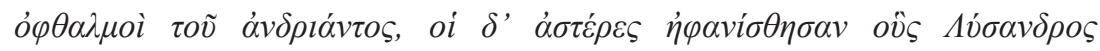

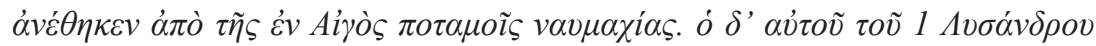

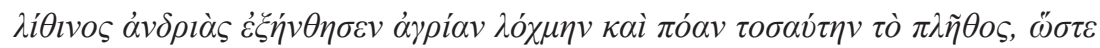

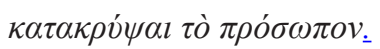

[...] Se le saltaron los ojos a su estatua, y desaparecieron las estrellas que Lisandro dedicó con motivo de la batalla naval de Egospótamos y de la estatua de piedra del propio Lisandro brotó una salvaje espesura y hierba en tal cantidad que ocultó su rostro. ${ }^{84}$

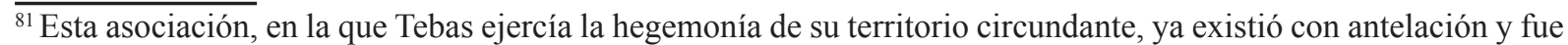
disuelta en el año 386 a. C. Acerca de esta Liga y de su temporal desaparición, vid. Buck, Robert J., Boiotia and the Boiotian League, 432-371 B. C., Alberta, University of Alberta Press, 1994.

${ }^{82}$ Cf. Fornis, César, Esparta. La historia ... op. cit., pp. 262-272.

${ }^{83}$ Diod. Sic., 15, 50, 2.

${ }^{84}$ Plut., Mor. 397F. Traducción de Mercedes López Salvá, Francisca Pordomingo Pardo y José Antonio Fernández Delgado, Madrid, Editorial Gredos, 1995.
} 
Este parece ser el final de las anteriormente fluidas relaciones entre Esparta y el oráculo de Delfos ${ }^{85}$. A lo largo de su historia, desde su configuración como polis y por motivaciones esencialmente políticas, los espartanos vincularon su trayectoria con el santuario délfico. En esta ocasión, en la que el poderío lacedemonio pareció tocar fondo, los espartiatas eligieron, también, interpretar su decadencia a través del oráculo mediante paranormales, pero simbólicos, acontecimientos que representarían el sentir generalizado tras la derrota de Leuctra y que fueron, posteriormente, recogidos por los autores de la Antigüedad. Curiosamente, las mismas fuentes que nos informan de las señales de la providencia hacia la caída de Esparta tienen en cuenta una vieja y famosa profecía, también délfica, convertida tras el 371 a. C. en proverbio. Dicho oráculo (evidentemente, una construcción post eventum) advertía sobre los peligros que entrañaría el apego de Esparta por la riqueza. Atendiendo a Diodoro, "el mismo Licurgo recibió de Delfos un oráculo respecto a la codicia, el cual se ha conservado en forma de proverbio: «La codicia,

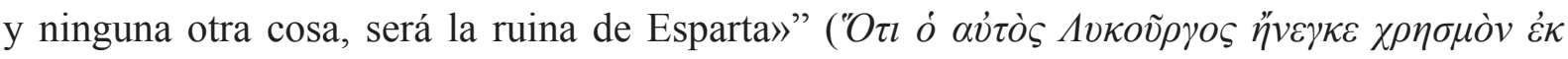

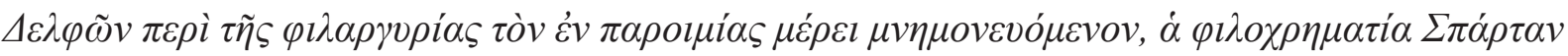

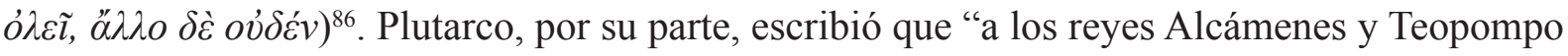

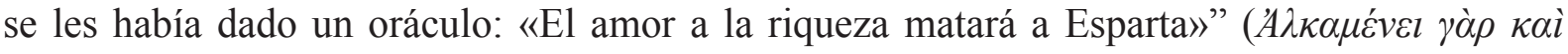

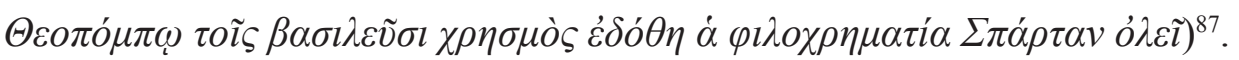

Ambos autores, que escribieron sus obras respectivamente en los siglos I a. C. y entre finales del I y principios del II d. C., relacionan el oráculo con la instauración de la Gran Retra y del sistema normativo espartano, aun con diferencias en su relato. La tradición refleja la crisis sociopolítica de Esparta tras la guerra del Peloponeso, que terminó por estallar una vez configurado el imperio espartano. En cualquier caso, parece que tanto el Sículo como el de Queronea escribieron bajo una fuerte influencia de la obra de Jenofonte quien, en el siglo IV a. C., compiló las normas del orden licurgueo en su Constitución de los lacedemonios y creó la vía moralizante por la que se explicó el fracaso de Leuctra, contraponiendo la Esparta "decadente" de su tiempo al modelo de virtud que habría representado siglos atrás ${ }^{88}$. Sirva, para cerrar este estudio, uno de los últimos fragmentos de este documento, extenso pero ilustrativo, en el que el historiador ateniense se lamenta de la degeneración de las costumbres espartanas y atribuye sin dudar la decadencia del poderío espartano a la insolencia de los lacedemonios hacia los dioses:

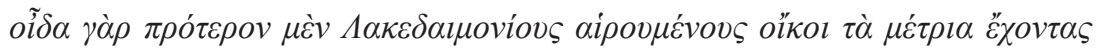

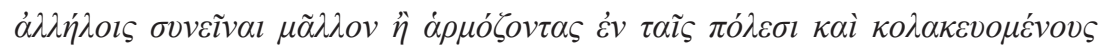

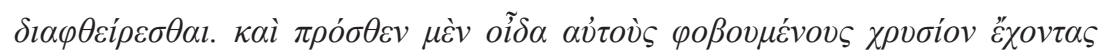

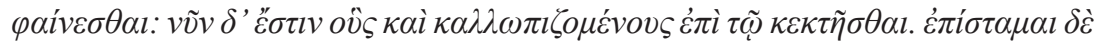

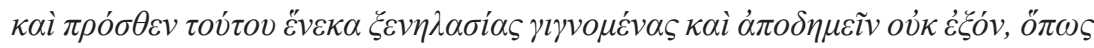

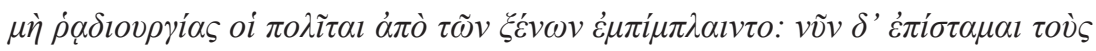

\footnotetext{
${ }_{85}^{85}$ Jacquemin, Anne, "Sparte et Delphes... op. cit.”, p. 145.

${ }^{86}$ Diod. Sic., 7, 12, 5.

${ }^{87}$ Plut., Mor. 239F.

${ }^{88}$ Fornis, César, El mito de Esparta. Un itinerario por la cultura occidental, Madrid, Alianza Editorial, 2019 , p. 45.
} 


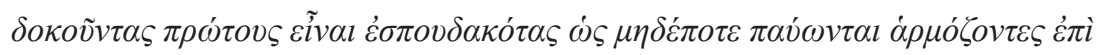

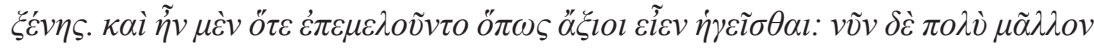

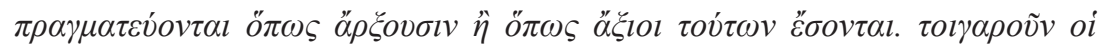

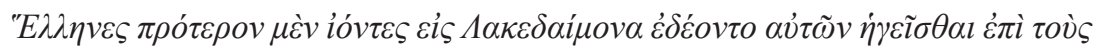

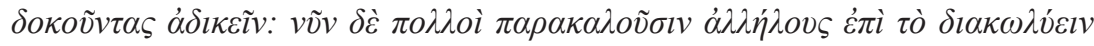

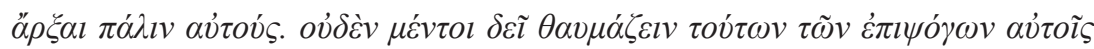

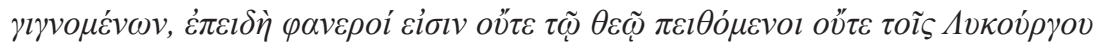

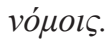

Yo sé que antiguamente los lacedemonios preferían vivir todos juntos en su patria con lo justo y no exponerse a las corruptas influencias y lujos como gobernantes de estados vasallos. Y también sé que en épocas pasadas temían que se les descubriera en posesión de oro, aunque hoy hay algunos que incluso se jactan de sus muchas posesiones. Igualmente sé que antes se recurría a expulsar a los extranjeros y que los lacedemonios consideraban ilegal viajar al extranjero para que los ciudadanos no se contaminaran con su molicie; ahora, por el contrario, no tengo dudas de que la mayor ambición de algunos consiste en conseguir ser gobernante en cualquier ciudad de fuera. Hubo un tiempo en que se ufanaban de ser auténticos líderes; ahora en cambio se interesan más por mandar que por merecer el mando. Hace años los griegos acudían a los lacedemonios para pedirles que tomaran el mando contra quienes les habían agraviado; y en cambio ahora son muchos los que se unen para impedir que renazca la hegemonía de Esparta. Pero es natural, y no hay que extrañarse de que se les haga este tipo de reproches, pues está absolutamente claro que ahora no obedecen al dios ni a las leyes de Licurgo. ${ }^{89}$

\section{Consideraciones finales}

La victoria de Esparta en la guerra del Peloponeso supuso un punto de inflexión no solo en su política interna, sino también en su idiosincrasia religiosa. Las fuertes disensiones de su clase dirigente, anunciadas ya desde décadas atrás, motivaron un cambio en las relaciones que la polis lacedemonia mantenía con las instituciones religiosas: la otrora sintonía que la vinculaba, particularmente, con el oráculo délfico dio paso a un uso partidista de sus profecías en pos de las ambiciones políticas de las diferentes facciones que se disputaban el devenir de la política exterior espartana. El triunfo de un punto de vista imperialista estuvo acompañado de un flujo de capital y de una nueva generación de espartanos, enardecida por el ejemplo de

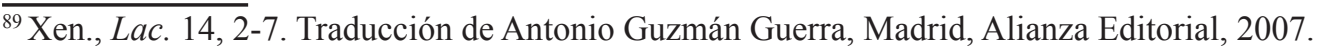


Lisandro y dispuesta a superar los viejos valores tradicionales (fundamentados en el refugio dentro de las fronteras del Peloponeso y en un ordenamiento constitucional hipotéticamente inmutable) para abrir una nueva etapa, revolucionaria en la política interna y agresiva en el plano exterior, en la que no había cabida para las limitaciones impuestas por los grandes oráculos. Abandonado el espíritu bajo el cual los espartiatas se convirtieron en indiscutibles dueños del destino de la Hélade, resulta comprensible que Jenofonte encontrara una relación entre una supuesta decadencia espartana y la renuncia a seguir los férreos dictados licurgueos; perspectiva esta que ha trascendido a través de los autores posteriores. No obstante, el principio del fin de la preponderancia lacedemonia sobre Grecia no es más que la prueba de que el mirage espartano, la ilusión de una supuesta igualdad socioeconómica entre los ciudadanos de la polis, distaba mucho de representar una realidad. Esparta continuó constituyendo una potencia a tener en cuenta, pero las pugnas por el poder y por asumir el mando de las relaciones exteriores fueron un lastre durante el siglo IV a. C. ${ }^{90}$. En este sentido, no deja de resultar interesante la transformación experimentada por el recurso a la religión que, si bien contribuyó a consolidar el dominio peloponesio en la centuria anterior, pasó a convertirse en un arma arrojadiza en el nuevo escenario geopolítico.

\footnotetext{
${ }^{90}$ Tal y como apunta Jones, Arnold Hugh M., Sparta, Oxford, Barnes \& Noble Inc., 1967, p. 148, tras la batalla de Leuctra y la muerte de Agesilao "Esparta casi desaparece de la historia".
} 